\title{
ANALYZING ENGLISH LANGUAGE TEACHING METHODS
}

\section{Prof. Dr. Jagdish Joshi}

\section{Mr. Tapan Shah}

\section{$\underline{\text { Abstract: }}$}

In the field of English Language Teaching there have been contentions and counter contentions about the role of various methods, approaches and techniques in learning the language. Throughout the hundreds of years, these strategies and methodologies have been fundamentally all through support in educational programs. Methodology is one of the significant components to actualize the objective of education in showing in teaching learning process especially in English classes. To give the data about wonderful strategies is the primary reason for this logical composition. Since English has been instructed till these days, in this manner, this paper is to improve the information of educational specialists particularly in technique for teaching English. The strategies are explained plainly as far as the standards are concerned. The standards are normal for showing learning process, nature of guidance, taking care of the students' sentiments and feelings, the job of local language of students, the language abilities that are accentuated, and the method for instructor's reaction to students' mistakes.

Key Words: Methodology, Teachers, English Language, Principles, Learner, Accentuate 


\section{Introduction:}

Indians interacted with the English language since the foundation of East India Company in the year 1612. Be that as it may, the spread of the language occurred when the British moved toward becoming the standards of this nation. In 1813, English language was presented as a medium of instruction at all the levels of education. Reformers like Rajaram Mohan Roy understood the significance of English and found in it the guarantee of modernization and freedom. He Favored it. This opened the door for English in India. Lord Macaulay (1835) wanted to deliver through English education" a class of people Indian in blood and colour but English in taste, in opinion, in morals and in intellect". Post- independence changed the status of English, yet it didn't influence the place of English in Indian life or education. English was never again the language of rulers. In any case, it kept on being the language of world class. The constitution of India, embraced in 1950, had conceived Hindi as the main official language of the association of India, while English was to proceed for 15 years. The was passionately restricted by the states in the south. Therefore, English was received as the Associate Official language by an act of parliament in 1963 and affirmations have been given that it will keep on being linguafranca as long as the non-Hindi talking individuals need it. Despite the fact that English was acknowledged as Associate Official Language, it didn't imply that it was to be acknowledged as a medium of guidance in Indian schools. Mother tongue turns into the main decision as the mode of guidance.

The Three language formula states that every child in school has to read at least three languages:

(1) The regional language

(3) English and non- Hindi regional language in Hindi speaking areas.

In 21th century English is as yet the second language/third language, for all intents and purposes it is picking up significance in all social statuses. In all the propelled conditions of India, increasingly English medium schools are being opened, individuals are slanted more to send their youngsters to English medium schools. Auxiliary instruction through mother tongue is looked downward on by not just the rich individuals yet in addition by white collar class individuals of India. International schools in India are the well known decision among Indian guardians. 


\section{Objective of Teaching English}

We know it very well that teaching of any subject is a social and cultural action. It isn't so natural to teach any subject as it shows up while teaching, an educator needs to remember the points and objectives of his subject. As it were, we can say that educating of any subject turns out to be much viable when the instructor is completely aware of the points and targets of teaching of that subject. A decent teacher believes that his teaching ought to be powerful. We all know it very well that the fundamental guideline of teaching is "comprehend what you do and just do what you know ". Teaching requires certain headings. All things considered, achievement of instructing relies upon the points and objectives of teaching.

Indian people think about English as a second language. It isn't the medium of instruction for a greater part of the students. It is an instrument, methods for obtaining learning. The point of teaching English in India is to assist students with acquiring practical command of English. As it were, It implies that students ought to have the option to comprehend communicate in English, read and write in English.

Since the commencement of teaching languages various distinctive teaching methodologies and strategies have been attempted and tried with some being more prominent and compelling than others. In case you're simply starting your profession, it is advantageous to be acquainted with a couple of these.

\section{The Direct Method}

Direct Method is also called the Natural Method or the Reformed Method.

The strategy Direct is named "direct" in light of the fact that importance ought to be associated straightforwardly with the objective language without interpretation in to the second language. The Direct teaching method is a technique for foreign and second language teaching which comprise that lone the objective language ought to be utilized in class and significance ought to be conveyed "Directly" by partner discourse shapes with activity, objects, mime, gesture and situations.

In the event that you've at any point heard the Direct Method being taught, you may have properly confused it with some kind of military drill, which isn't far-removed as it was first 
Towards Excellence: An Indexed, Refereed \& Peer Reviewed Journal of Higher Education / Dr. Jagdish Joshi \& Mr. Tapan Shah / Page 102-109

settled in France and Germany in the mid 1900's to help soldiers to impart in a second language rapidly. It's utilized to show different languages not simply English, and the fundamental thought of the Direct Method is that it just uses the objective language that the students are attempting to learn.

Its fundamental center is oral aptitude and it is taught by repetitive drilling. Grammar is instructed using an inductive way and students need to attempt to figure the principles through the teacher's oral introduction.

\section{The Grammar Translation Method}

It is also called the Classical Method. Much the same as its name proposes, this technique for teaching English is grammar substantial and depends a great deal on translation. This is the customary or 'traditional' method for learning a language it's still normally utilized when adapting a few dialects. A few nations lean toward this style of educating and the primary thought behind this technique is that the students gain proficiency with all syntax rules, so they're ready to decipher various sentences. This is especially regular for those understudies who wish to think about writing at a more profound level.

In GTM the job of local language is significant on the grounds that it utilizes local language or L1 to comprehend the objective language. Surprisingly, whatever the students find out about the objective language they will reflect it to their local language (Celce-Murcia, 2001:6. Darker, 2007:19. Harmer, 2007:63). Besides, while learning about Grammar, the teachers and the students attempt to comprehend the syntax by utilizing the local language. The teacher investigates the punctuation of target language by utilizing local language and the vast majority of the training learning procedures is finished by utilizing the local language too

\section{The Audio Lingual Method}

The Audio Lingual Method otherwise known as the New Key Method or Army Method is based on a behaviorist theory that things are able to be learned by constant reinforcement. However, just like in the army when someone behaves badly (or in this case bad use of English), the learner receives negative feedback and the contrary happens when a student demonstrates good use of English. 
Towards Excellence: An Indexed, Refereed \& Peer Reviewed Journal of Higher Education / Dr. Jagdish Joshi \& Mr. Tapan Shah / Page 102-109

This is related to the Direct Method and just like its predecessor it only uses the target language. The biggest difference between the Audio Lingual Method and the Direct Method is its focus of teaching. The Direct Methods focuses on the teaching of vocabulary whereas the Audio Lingual Method focuses on specific grammar teachings.

\section{The Structural Approach}

As the name proposes, the technique is about structure. The thought is that any language is comprised of complex grammar rules. These guidelines, as per this methodology should be learnt in a particular request, for instance the coherent thing is show the action word "to be" preceding training the present nonstop which requires utilizing the helper type of the action word "to be."

\section{Suggestopedia}

This is a behaviorist theory and identified with pseudoscience. This strategy depends intensely on students' conviction about the technique's viability. This hypothesis is planned to offer students different decisions, which encourages them become increasingly in charge of their learning.

It depends a great deal on the atmosphere and the physical surroundings of the class. It's fundamental that all students feel similarly great and sure. At the point when teachers are preparing to utilize the Suggestopedia technique, there's a ton of craftsmanship and music included. Each Suggestopedia exercise is separated into three distinct stages - 1. Deciphering 2.Concert Session 3. Elaboration

\section{Total Physical Response}

Total Physical Response, also called TPR is a methodology that follows 'learning by doing'. Beginners will learn English through a progression of dreary activities, for example, "Stand up", "Open your book", "Close the door", and "walk to the window and open it." With TPR, the most significant aptitude is aural appreciation and everything else will pursue normally later.

\section{Communicative Language Teaching (CLT)}


Towards Excellence: An Indexed, Refereed \& Peer Reviewed Journal of Higher Education / Dr. Jagdish Joshi \& Mr. Tapan Shah / Page 102-109

The idea behind this methodology is to enable students to convey all the more adequately and effectively in sensible circumstances that they may wind up in. This kind of teaching includes concentrating on significant capacities like recommending, expressing gratitude toward, welcoming, grumbling, and requesting bearings to give some examples. CLT strategy gives the guidance to the students to secure the vocabulary of target language by not utilizing the local language as the reflection. Besides, the instructor teaches the students to procure the vocabulary through true settings (Brown, 2007:46). One model is by utilizing genuine picture, realia or the execution of the word in sentence or expression.CLT urges the understudies to speak with target language without concentrating on syntax first (Larsen-Freeman, 2011:115. Hiep: 2005:4)

\section{The Silent Way}

The Silent Way underscores student self-governance. The teacher demonstrations just as a facilitator attempting to urge students to be progressively dynamic in their learning. The primary of along these lines of educating is for the students to state practically nothing, so students can assume responsibility for their learning. There's a major emphasis on pronunciation and a large chunk of the exercise centers around it. This strategy for learning English pursues an auxiliary prospectus and sentence structure, vocabulary and elocution are always penetrated and reused for fortification. The instructor assesses their understudies through cautious perception, and it's even conceivable that they may never set a formal test as students are urged to address their very own language blunders.

\section{Community Language Learning}

This is most likely one of the English instructing techniques where the student feels the most secure as there's an extraordinary accentuation on the relationship and bond between the student and teacher. In contrast to a ton of different techniques and methodologies of showing English as a Second Language, a great deal of the L1 (primary language) is utilized for interpretation purposes.

\section{Task Based Language Learning}

The principle point of this way to deal with learning is task fulfillment. Generally, significant and fascinating assignments are set by the teacher and students are required to draw on their prior 
Towards Excellence: An Indexed, Refereed \& Peer Reviewed Journal of Higher Education / Dr. Jagdish Joshi \& Mr. Tapan Shah / Page 102-109

learning of English to finish the undertaking with as couple of blunders as could reasonably be expected.

\section{The Lexical Approach}

The Lexical prospectus or approach depends on computer studies that have recently distinguished the most regularly utilized words. This methodology in instructing centers on vocabulary securing and showing lexical lumps arranged by their recurrence and use. Instructors of the Lexical Approach place an extraordinary accentuation on genuine materials and reasonable situations for progressively profitable learning.

\section{Reference:}

Brown, H. D. Teaching by Principle; An Interactive Approach to Language Pedagogy. Third Edition. New York: Pearson Longman. 2007.Print.

Celce-Murcia, M. Teaching English as a Second or Foreign Language. Third Edition. Heinle: Language Learning. 200.Print.

Harmer, J. The Practice of English Language Teaching. Fourth Edition. Cambridge: Pearson Longman. 2007.Print.

Hiep, P.H. "Imported” Communicative Language Teaching Implications for Local Teachers." Journal of English Teaching Forum. 43 (4) 2-9. 2005. 
Towards Excellence: An Indexed, Refereed \& Peer Reviewed Journal of Higher Education / Dr. Jagdish Joshi \& Mr. Tapan Shah / Page 102-109

Larsen-Freeman, D and Anderson, M. Techniques \& Priciples in Language Teaching Oxford: Oxford University Press. 2011.Print.

Thompson, G. Some Misconceptions about Communicative Language Teaching. ELT Journal. 50 (1) 9-15. 1996.Print.

William O'Grady, Michael Dabrovolsky, and Mark Aronoff, Contemporary Linguistics: An Introduction, New York: St. Martin's Press, 1993.

\section{Dr. Jagdish Joshi \\ Professor-Director}

UGC-Human Resource Development Centre

Gujarat University, Ahmedabad

\&

Mr.Tapan P.Shah

Ph.D Research Scholar, Gujarat University, Ahmedabad

Assistant Prof. Aroma College of Commerce

Usmanpura, Ahmedabad.

tpnshah87@gmail.com 